\title{
The P-A-C-I-E-N-T-E Protocol: An instrument for breaking bad news adapted to the Brazilian medical reality
}

\author{
Carolina Rebello Pereira ${ }^{1}$, Marco Antônio Marchetti Calônego², Lino Lemonica³ ${ }^{3}$ Guilherme Antonio Moreira de Barros* \\ ${ }^{1} \mathrm{MD}$, Anesthesiologist, Specialized in Pain and Palliative Care. PhD Professor, Pontifícia Universidade Católica, Sorocaba. PhD from the Anesthesiology Graduate Program at Faculdade de Medicina de Botucatu, \\ Universidade Estadual Paulista (Unesp), Botucatu, SP, Brazil \\ ${ }^{2}$ Attorney and Masters Student at the Anesthesiology Graduate Program at Faculdade de Medicina de Botucatu, Unesp, Botucatu, SP, Brazil \\ ${ }^{3} \mathrm{MD}$, Anesthesiologist, Specialized in Pain. Retired Adjunct Professor, Department of Anesthesiology, Faculdade de Medicina de Botucatu, Unesp, Botucatu, SP, Brazil \\ ${ }^{4} \mathrm{MD}$, Anesthesiologist, Specialized in Pain and Palliative Care. Assistant PhD Professor, Department of Anesthesiology, Faculdade de Medicina de Botucatu, Unesp, Botucatu, SP, Brazi
}

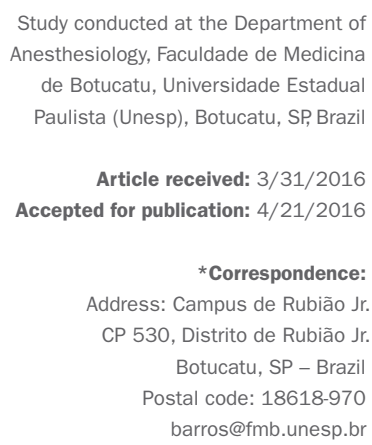

Study conducted at the Department of Anesthesiology, Faculdade de Medicina de Botucatu, Universidade Estadual Paulista (Unesp), Botucatu, SP, Brazil

Article received: $3 / 31 / 2016$ Accepted for publication: 4/21/2016 ${ }^{*}$ Correspondence: Address: Campus de Rubião Jr. CP 530, Distrito de Rubião Jr. Botucatu, SP - Brazil

Postal code: 18618-970 barros@fmb.unesp.br

http://dx.doi.org/10.1590/1806-9282.63.01.43

\section{SUMmARY}

Objective: There are plenty of published tools for breaking bad medical news; however, none of them is culturally appropriate to our reality or published in the Brazilian literature. This study proposes a genuinely Brazilian communication tool and evaluates its acceptance among doctors and nurses.

Method: This was a prospective study. The data were collected after specific training of doctors and nurses on the bad news communication techniques based on the P-A-C-I-E-N-T-E ("patient," in Portuguese) Protocol. This instrument is in accordance with the Brazilian reality and was based on the SPIKES communication tool.

Results: The worst task to be performed during communication is "talking about death" followed by "discussing the end of curative treatment attempts" and "diagnosis" itself. Among the respondents, $48 \%$ reported they did not receive formal training for communicating. Also, $52 \%$ of respondents do not use any systematic approach in their daily practice when communicating with patients, but $97 \%$ considered the proposed P-A-C-I-E-N-T-E Protocol as a useful and appropriate communication tool.

Conclusion: The P-A-C-I-E-N-T-E Protocol proved to be suitable to the Brazilian context.

Keywords: palliative care, protocol, communication.

\section{INTRODUCTION}

Breaking bad news to a patient can be considered as one of the moments of greatest anxiety in medical practice. ${ }^{1-3}$ Communication protocols are intended to minimize this stress, facilitating the development and maintenance of a good doctor-patient relationship. ${ }^{4-7}$

Bad news can be defined as the revelation of a diagnosis of a potentially life-threatening disease, such as cancer, as well as the failure of a curative therapy, but also include the discussion of a poor prognosis and the proximity of death. ${ }^{1,4,6}$ According to the Brazilian Code of Medical Ethics (Chapter V, art. 34), ${ }^{8}$ breaking bad news is a medical act that should not be delegated. However, nurses are professionals that are very present in patient care, and will often repeat and explain what was said by the doctors. These professionals also have their repertoire of bad news to communicate to the patient, such as the need for a new venous access to be punctured. ${ }^{9}$
The way that bad news is transmitted generates a result that is more harmful to the patient and their family than actual content informed. ${ }^{4,5}$ Thus, specific communication protocols and training can encourage the establishment of empathy and trust between the patient and his/her doctor.

There are communication protocols proposed in the international literature that are effective in reducing the stress of professionals as well as facilitating the process of informing patients. ${ }^{4,6,10-13}$ However, there are no genuinely Brazilian protocols proposed in the literature, or even protocols that have been adapted.

The cultural and ethnic specificities of our country evidently require a different type of communication or approach from those already existing.

The main objective of our study was to propose a communication protocol in Brazilian Portuguese that is easily memorable and culturally adapted to the Bra- 
zilian reality, evaluating its acceptance among doctors and nurses.

It also aims to evaluate the perceptions of nurses and doctors about the process of breaking bad news.

\section{Method}

After approval by the Institutional Research Ethics Committee and obtaining informed consent, 226 questionnaires were applied to higher level health professionals (doctors and nurses). This is a prospective study conducted at a single research center, where the data was collected over a period of two years, after specific training of health professionals in communication skills for breaking bad news and the use of an instrument to facilitate the process. This instrument is based on a model adapted from the SPIKES Protocol, using a mnemonic code adapted to Brazilian reality, called the P-A-C-I-E-N-T-E Protocol (Chart 1). The evaluation of the appropriateness and usefulness of the protocol was based on the opinion of the participants in the study, as presented in the research questionnaire.

In addition to the six steps transcribed by SPIKES, in the adapted protocol there is a seventh stage, namely: "Don't abandon the patient," which is paramount to meeting patients' expectations. Patients are often afraid of death and how it will occur, resulting in fear of being abandoned. ${ }^{14}$ The training sessions were conducted by the authors during realization of scientific events promoted by several medical societies (the Brazilian Society for Study of Pain - SBED; the Brazilian Society of Anesthesiology - SBA; and the Society of Anesthesiology in the State of São Paulo - SAESP) in an itinerant manner.

After being submitted to the training, which was characterized by a formal expository lesson on communicating bad news and presentation of the P-A-C-I-E-N-T-E Protocol, followed by a practical "role play" activity, doc- tors and nurses of any specialty were invited to participate in the study. There was no limitation of participants in relation to sex or age.

Only questionnaires that were filled out incompletely or were unreadable were excluded from the sample, leading to the total exclusion of 26 questionnaires. Participation was free, and included all participants of the training sessions, as there was no refusal to participate.

The training offered initially consisted of a brief introduction about the importance of breaking bad news in the practice of health professionals. The P-A-C-I-E-N-T-E Protocol, a mnemonic information method consisting of seven steps, was presented as described below.

\section{P - Prepare}

Health professionals should be prepared before transmitting bad news appropriately. First, the veracity of the information to be revealed must be confirmed by consulting the medical record. It is also recommended to consult the medical literature in order for any possible doubts to be resolved. It is necessary to prepare the environment properly, ensuring total privacy and comfort. Preferably, there should be no physical barriers standing between the doctor and the patient. The professional should ensure that no unexpected interruptions will occur during communication and should sit at the same height as the patient.

\section{A - Assess how much the patient knows and how much they want to know}

It is important to assess the patient's level of knowledge about their diagnosis. Similarly, question what level of information the patient would like to receive at this time, or if they actually do not wish to be informed of their diagnosis. In this case, the patient may indicate someone they trust to receive the information on their behalf.

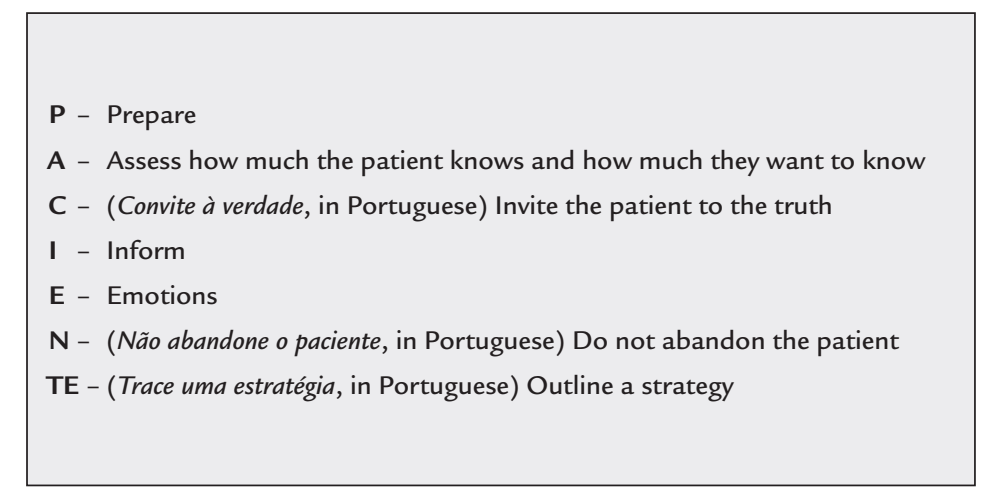

CHART 1 Definition of the steps of the communication protocol that is composed, in a mnemonic way, by the word P-A-C-I-E-N-T-E. 


\section{C - Invite the patient to the truth}

In this step the patient is informed of the existence of bad news. Use phrases such as: "I'm sorry, but I believe I don't have good news." The patient is thereby offered the possibility of changing their mind as to whether they want to be informed or not. In some situations, the patient may be quiet and not continue beyond the "Invite the patient to the truth" stage. This attitude may indicate that the patient needs more time to understand and work out what they were told.

\section{I - Inform}

The best strategy is to wait for the time required by the patient and offer space for them to "invite" the doctor to share the information and ask directly about their diagnosis, prognosis or results. ${ }^{4-6}$ The relevant information about the state of the patient's health can then be shared at a sufficient amount, speed, and quality, and at the desired amount, so that the patient can make decisions about their life or offer informed consent about their treatment. Avoid a precise report of the prognosis, as doctors tend to overestimate life expectancy. Offer information clearly and honestly, trying to keep the patient's hopes up while being realistic as to treatment options. Do not use euphemisms but choose the right keywords, such as "cancer" and "metastasis," explaining their significance..$^{3-6,15,16}$

\section{E - Emotions}

After the information has been revealed, the patient needs time to understand and react to the bad news. Keep tissues nearby. Allow patients to express themselves. Use touch as a form of communication and comfort. Clarify the patient's doubts, so that they feel accepted and protected.

\section{$\mathrm{N}$ - Do not abandon the patient}

Ensure that your patient will receive medical monitoring Make a commitment not to abandon them, regardless of the outcome.

\section{T and E - Outline a strategy}

Plan the care to be offered and treatment options with the patient. Include interdisciplinary care in the plan, whenever possible. Request monitoring by other doctors who can assist in the control of symptoms..$^{3-6,15-18}$

\section{Statistical analysis}

For the statistical analysis, we used the SPSS Statistics software version 17.0.0. For comparison of the ages in relation to sex and profession, we used Student's t-test. To study the association between the variables, ages were divided into four groups $(\mathrm{A}=30$ years; $\mathrm{B}=30$ to 39 years; $\mathrm{C}=40$ to 49 years; and $\mathrm{D} \geq 50$ years). Fisher's exact test and Chi-square test were used in relation to these associations. The level of significance adopted was $5 \%$.

\section{Results}

Nine out of the total number of questionnaires applied were excluded due to illegibility or completion errors, and 17 due to incomplete data. The collection was interrupted when 100 valid questionnaires from doctors and 100 from nurses were obtained. Nurses were predominantly female (90 participants, $\mathrm{p}<0.05$ ), with no difference between the sexes in the group of doctors. In all included subjects, however, the female sex represented $72 \%$ of the sample $(p<0.05)$. There was a homogeneous distribution of age groups, but a discreet predominance of those between 30 and 39 years of age, which accounted for $37 \%$ of the sample, and is not statistically significant.

For $39.5 \%$ of respondents, the most difficult task to be performed during the communication is talking about death. However, 30.5 and $13 \%$ found it more difficult to discuss ending attempts at curative treatment and the diagnosis itself, respectively. The following tasks were considered in order of decreasing difficulty: notifying the recurrence of the disease, discussing the diagnosis, and involving the patient's family in the discussion.

When comparing the influence of the professional's gender on the difficulty encountered in the implementation of the tasks there was a coincidence, between men and women, as far as difficulty in discussing death. However, the second greatest difficulty for women was talking about the diagnosis, while for men it was talking about the end of the attempts at curative treatments $(p<0.05)$. Age or profession did not affect the perception of difficulties.

Forty-eight percent (48\%) of respondents reported not having received formal training on communication, while only $14 \%$ had specific lessons on the subject. However, $19.5 \%$ of the sample reported having improved their communication skills by observing other professionals and also attending lessons, while $18.5 \%$ had been exclusively trained by observing other professionals. There is no statistically significant difference between the age, sex or profession of the participants in this regard ( $p>0.05)$.

After completion of training with the P-A-C-I-E-N-T-E method, $49 \%$ of the individuals believed their ability to communicate bad news was reasonable, classified in descending order as good (25.5\%), poor (12.5\%), very good $(7.5 \%)$, and very poor (5.5\%). In this matter, there were no statistical differences between gender and age, although there was a statistical difference when comparing profes- 
sion. Only $10 \%$ of doctors assessed their ability to break bad news as "poor" or "very poor," while $26 \%$ of nurses considered their ability likewise (Figure 1).

Many difficulties are encountered when breaking bad news. The most important among those suggested in the questionnaire, according to $42.5 \%$ of participants, was "dealing with the patient's emotions," while "being honest without giving up hope" appeared in second place in order of difficulty, with $37.5 \%$. When gender differences are taken into account, male participants present greater difficulty in being honest and maintaining hope, while female participants have greater difficulty in dealing with emotions (Figure 2).

Doctors considered that the easiest step in the P-AC-I-E-N-T-E Protocol is "Prepare" (38\%), while nurses consider it is "Do not abandon the patient" (47\%). It is striking that none of the doctors considered the task "outlining a strategy" as the easiest. In relation to age, statistical differences were noted: younger groups have greater ease with "Do not abandon the patient;" the 40-49 years age group, with "Prepare," and the group over 50 years, with "Emotions."

Fifty-two percent (52\%) of the participants do not use any systematic approach in their daily practice when communicating with patients. Only $18 \%$ use an instrument; and $30 \%$ employ several techniques, albeit without a gen- eral plan. Surprisingly, approximately $97 \%$ of participants consider that the P-A-C-I-E-N-T-E Protocol is appropriate and useful in communicating bad news, according to the survey. These aspects were not influenced by gender, age or profession.

\section{Discussion}

It is known that one of the factors that most interferes in the communication of bad news to patients is the health professional's stress, which is usually related to a lack of specific training. ${ }^{19,20-23}$

Most people, regardless of their own cultural characteristics, would like to be aware of their diagnosis, even if it means accepting that they are terminally ill. ${ }^{6,11,13,24-26}$ This information is important to patients, as they start to show a greater degree of adaptation to reality, with lower levels of depression and anxiety, better adherence to treatment, more acceptance of interventions, and suitable monitoring of dosages and recommendations ${ }^{9,27}$ as well as preventing barriers between the family and the patient (conspiracy of silence). ${ }^{28}$ Furthermore, it prevents the patient receiving futile treatments and heroic interventions, creating false hopes and expectations in treatments. ${ }^{17,20,25,27,29-34}$

In Brazil, communication strategies are beginning to gain strength, but a protocol adapted to the Brazilian context has not yet been described. In accordance with

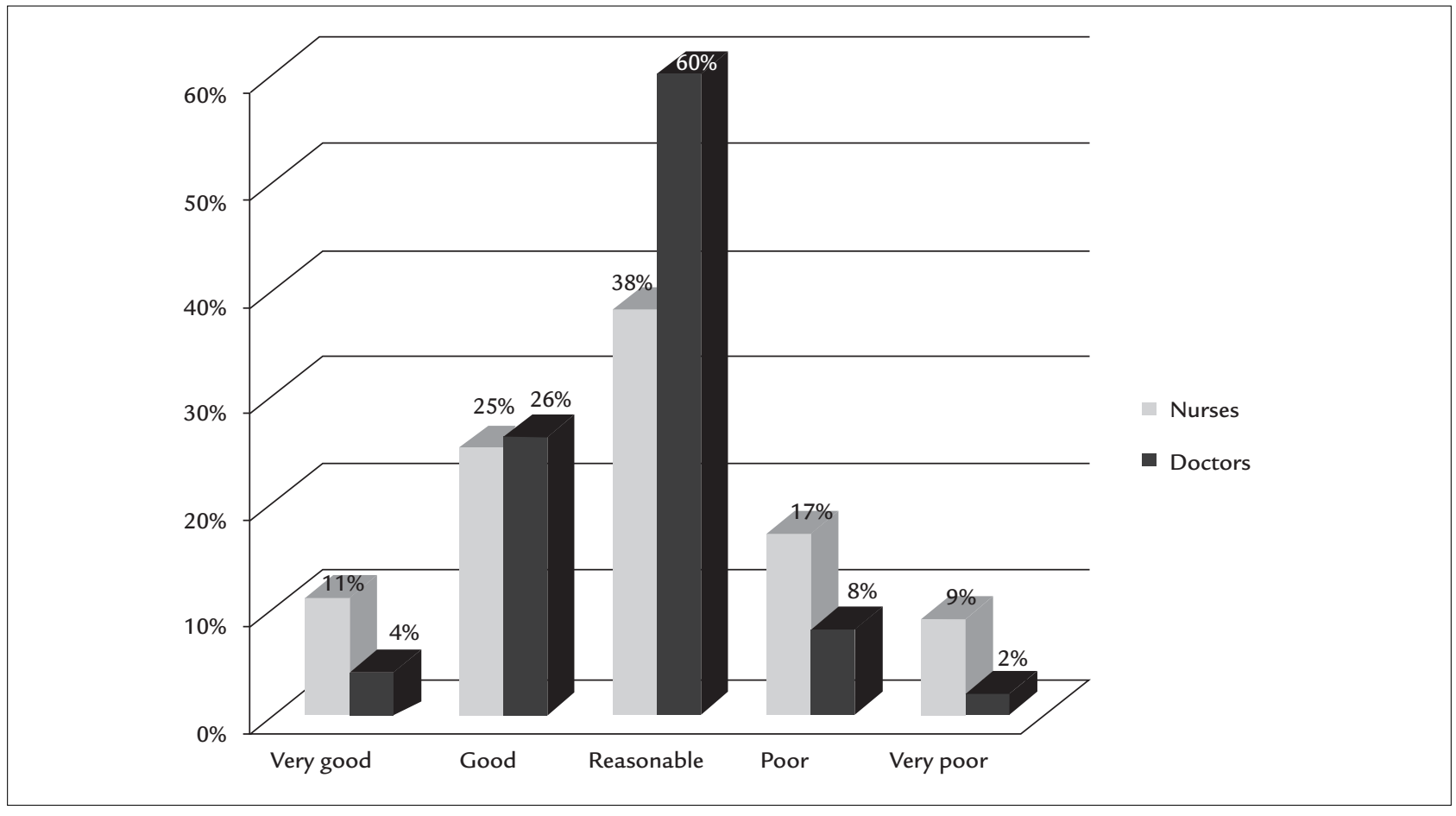

FIGURE 1 Perception of doctors and nurses on their ability to break bad news. 


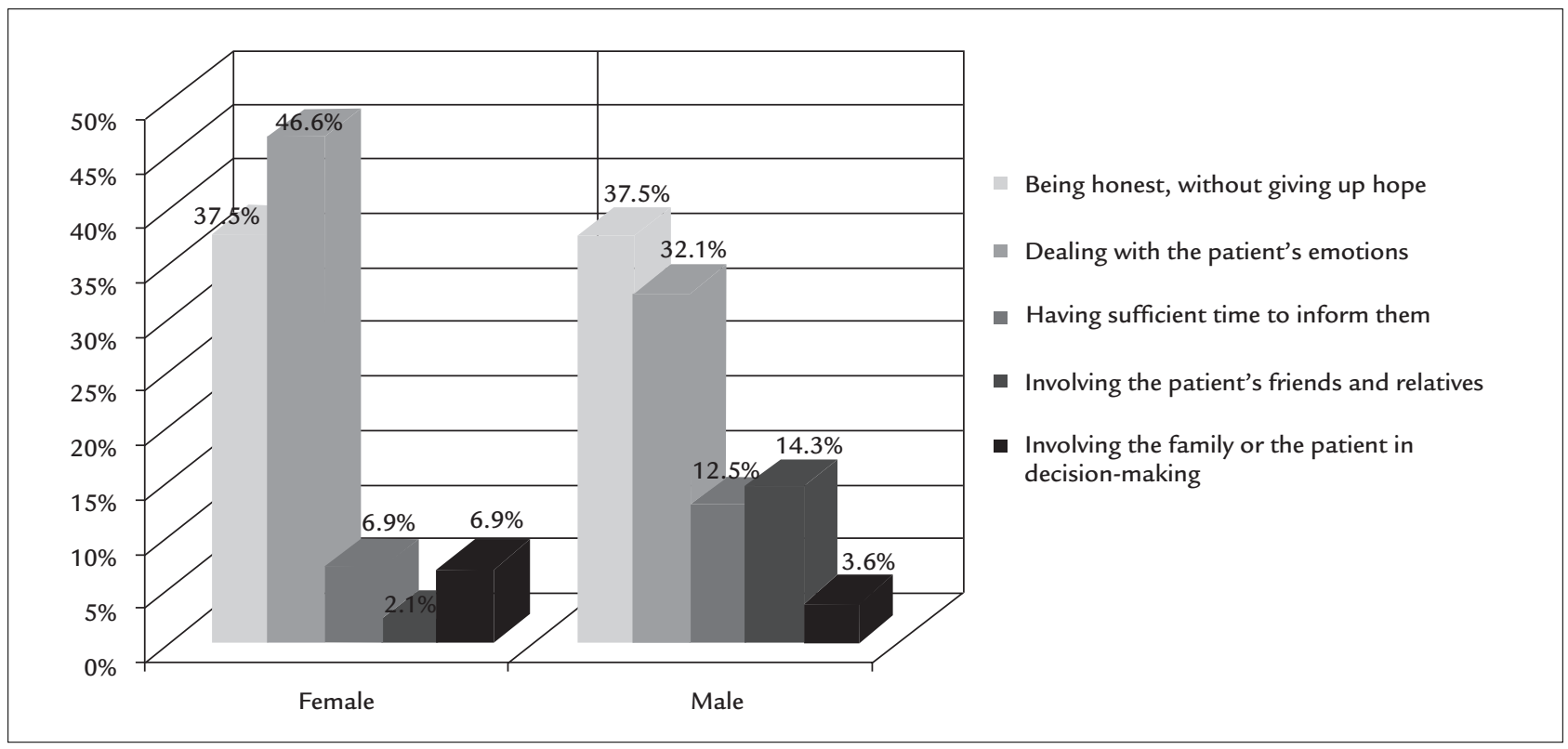

FIGURE 2 Differences in difficulties discussing bad news with patients between the genders of the participants.

this shortfall, we have proposed a protocol for breaking bad news based on the medical literature and in line with the cultural peculiarities of Brazil., ${ }^{4,11-13}$ This method is based on a mnemonic device using a word in Portuguese ("patient") to facilitate its use in the Brazilian context (Chart 1). Its objective is to facilitate diagnostic and prognostic information in a systematic and truthful manner, respecting autonomy, individuality, Brazilian culture, and the maintenance of hope.

In our study, the female gender was prevalent, especially among the group of nurses. Similar results to ours were found in an Iranian study published in 2010, involving the participation of 50 doctors and 50 nurses. ${ }^{23}$

In our study, $49 \%$ of respondents assessed their communication skills as being reasonable, and $18 \%$ as poor or very poor. Doctors presented better levels of confidence in their skills than nurses. The results of Arbabi (2010) regarding the self-reported ability of professionals in breaking bad news are equal to ours, that is, $40 \%$ of the doctors assessed their ability at disclosing bad news as "good and very good" and $22 \%$ as "weak and very weak," data similar to those of Buckman (2000). ${ }^{4,23}$ In our study, nurses evaluated their communication skills as worse when compared to doctors, with similar results found in the literature. ${ }^{23}$

In our sample, $44 \%$ of respondents had never received any type of training and, among those trained, $22.5 \%$ learned exclusively through observation of other professionals. Interestingly, a study published in the United
Kingdom showed similar figures: $49 \%$ of doctors had never received formal training, although most believe it to be useful in a clinical context. ${ }^{35}$ In general, as verified in our context, studies found a low percentage of professionals who had been trained in communicating bad news during their education., ${ }^{4,23}$

In line with the literature, there is a growing concern in changing the educational profile to include communication in the curricula. ${ }^{19,22}$ The Accreditation Council for Medical Education in the United States has already included communication with patients as a fundamental skill in the curriculum of residents and graduate students. ${ }^{10}$ Considering that, in our study, the percentage of professionals who received communication training does not present a significant difference in relation to the age of the interviewees, we can infer that there has been no important modification in teaching communication at medical and nursing schools in recent decades.

However, most of the health professionals interviewed in several studies believe that training on breaking bad news is important and has the potential of bringing benefits to their clinical practice. , 36,37 In our study, 97\% of the participants agreed that the P-A-C-I-E-N-T-E method could be useful in their professional practice.

We also assessed the potential difficulties and, consequently, the factors that cause anxiety in the process of breaking bad news. "Discussing death" and "discussing the end of attempts at curative treatment" were considered the most difficult tasks in our study. We therefore noted 
that issues related to the lack of possibility of finding a cure and, consequently, issues that are frequent in palliative care represent greater difficulties for health professionals than the disclosure of the diagnosis itself. ${ }^{18,38}$

In relation to the procedure for breaking bad news, dealing with the emotions of patients was the most difficult task indicated by our respondents. Most studies published in different cultural scenarios indicate that one of the difficulties cited and emphasized the most by health professionals in the communication process is, coincidentally, dealing appropriately with the emotions of patients and their families. $4,5,12,19,23$

The participants in our study aged 50 years or older showed less difficulty in dealing with patients' emotions, which points to the fact that greater clinical experience as well as maturity can facilitate moments of interaction with the emotions of patients and their families. ${ }^{17,23,38}$

One of the greatest challenges in the communication process is maintaining hope when bad news is revealed. ${ }^{3,4,12,15,21}$ In our study, $37.5 \%$ of respondents reported that this was the most difficult task. Certain attitudes and characteristics of doctors favor the preservation of hope among patients. These include the professional remaining up to date, demonstrating confidence, ensuring that patients receive appropriate pain treatment, providing realistic information about the future, providing an opportunity for questions and giving explanations about the disease using appropriate expressions such as "cancer" and "death.", 24 Knowledge of this fact increases the importance of the step "Outlining a strategy" in the proposed protocol.

Interestingly, unlike in other cultures, ${ }^{24}$ only a small percentage of the professionals we interviewed mentioned some difficulty or barrier in relation to family involvement in the process. This result may reflect characteristics of the Brazilian culture, in which family involvement is usual, and the family holds a role not only as a passive companion, but also participates in decision-making and in the demand for information. . $^{13,39,40}$

In relation to the seven steps of the protocol, participants judged "do not abandon the patient" as the easiest, followed by "prepare." It is probable that on account of the attributes of the profession of nurse, which brings them closer to the patient and family, most of the nurses mentioned "do not abandon the patient" as the easiest task. Doctors, on the other hand, indicated that "prepare" is the easiest task. This is possibly due to the fact that they have unrestricted access to the data needed, and all the theoretical knowledge related to the illness in question.
Generally, when bad news are given by a doctor, the patient needs time to digest what was said, or needs simpler vocabulary to understand the implications of the bad news. Nurses are the professionals who are present for a longer time providing patient care and will often be the ones to repeat and explain what was said by the doctors to the patient. ${ }^{41}$

This study has certain limitations, such as the fact that the sample was not distributed in a controlled manner, given that the scientific events where the training took place attract people from different regions of the country and from different specialties but who have a particular interest in the subject (treatment of pain and palliative care). It also does not specify the amount of professional experience of the participants. The gain in knowledge and communication skills regarding bad news, as given in the majority of publications on the subject, was only assessed subjectively by the participant, without the application of a formal assessment. ${ }^{42}$

There is a need to encourage the study of the subject in our midst, especially by researching preferences and needs of Brazilian patients.

\section{Conclusion}

Most of the literature available on this subject focuses on medicine and the patient in a European or American context, and is scarce in our country. ${ }^{10,19,43}$ This study quantifies and qualifies the preferences and experiences of doctors and nurses in our reality.

Communication should be one of the skills developed in the curricula of health education institutions since the beginning of studies, when clinical knowledge is introduced. The P-A-C-I-E-N-T-E Protocol has been proposed as a tool to direct and facilitate communication and was shown to be practical and useful for the majority of the participants in this study. The health professional's common sense and experience should be considered when using the protocol.

\section{Resumo}

Protocolo P-A-C-I-E-N-T-E: instrumento de comunicação de más notícias adaptado à realidade médica brasileira

Objetivo: Existem inúmeros protocolos de comunicação de más notícias; porém, nenhum método na literatura nacional é culturalmente adequado à nossa realidade. Este estudo propõe um método de comunicação adaptado e avalia sua aceitação entre médicos e enfermeiros brasileiros. 
Método: Trata-se de um estudo prospectivo cujos dados foram coletados após treinamentos específicos de médicos e enfermeiros sobre as técnicas de comunicação de más notícias. Foi empregado instrumento mnemônico chamado Protocolo P-A-C-I-E-N-T-E. Esse instrumento, em concordância com a realidade brasileira, foi baseado no Protocolo SPIKES de comunicação.

Resultados: Verificou-se, entre os profissionais da saúde, que a pior tarefa a ser executada durante a comunicação é "falar sobre a morte", seguida de "discutir o fim das tentativas de tratamento curativo" e o "diagnóstico" em si. Do total dos entrevistados, $48 \%$ relataram não terem recebido treinamento formal sobre comunicações. Verificou-se, ainda, que $52 \%$ dos participantes não utilizam qualquer abordagem sistematizada na prática diária ao se comunicarem com os pacientes, mas $97 \%$ consideraram o protocolo proposto útil e adequado.

Conclusão: O Protocolo P-A-C-I-E-N-T-E, proposto como ferramenta para direcionar a comunicação, mostrou-se adequado à nossa realidade.

Palavras-chave: cuidados paliativos, protocolo, comunicação.

\section{REFERENCES}

1. Buckman R. Talking to patients about cancer. BMJ. 1996; 313(7059):699-700.

2. Costantini M, Morasso G, Montella M, Borgia P, Cecioni R, Beccaro M, et al. Diagnosis and prognosis disclosure among cancer patients. Results from an Italian mortality follow-back survey. Ann Oncol. 2006; 17(5):853-9.

3. Hagerty RG, Butow PN, Ellis PM, Lobb EA, Pendlebury SC, Leighl N, et al Communicating with realism and hope: incurable cancer patients' views on the disclosure of prognosis. J Clin Oncol. 2005; 23(6):1278-88.

4. Baile WF, Buckman R, Lenzi R, Glober G, Beale EA, Kudelka AP. SPIKES-A six-step protocol for delivering bad news: application to the patient with cancer. Oncologist. 2000; 5(4):302-11.

5. Buckman R. Communications and emotions. BMJ. 2002; 325(7366):672.

6. Emanuel LL, Ferris FD, von Gunten CF, Von Roenn J. Communicating effectively. In: Education in Palliative and End-of-life Care-Oncology EPEC-O Chicago: The EPEC Project; 2005. p. 1-13.

7. VandeKieft GK. Breaking bad news. Am Fam Physician. 2001; 64(12):1975-8.

8. Conselho Federal de Medicina CFM. Código de Ética Médica. Resolução CFM 1931. 2009 [cited 2016 Mar]. Available from: http://portal.cfm.org. $\mathrm{br} /$ index.php?option=com_content $\&$ view $=$ category\&id=9\& Itemid=122.

9. Vaccari A. Importância da comunicação no processo de adesão [dissertation]. Porto Alegre: Faculdade de Enfermagem, Universidade Federal do Rio Grande do Sul; 2008 [cited $2016 \mathrm{Mar}$ ]. Available from: http://www.lume.ufrgs.br/ handle $/ 10183 / 31297$

10. Back AL, Arnold RM, Baile WF, Fryer-Edwards KA, Alexander SC, Barley GE, et al. Efficacy of communication skills training for giving bad news and discussing transitions to palliative care. Arch Intern Med. 2007; 167(5):453-60.

11. Kirk P, Kirk I, Kristjanson LJ. What do patients receiving palliative care for cancer and their families want to be told? A Canadian and Australian qualitative study. BMJ. 2004; 328(7452):1343

12. Buckman RA. Breaking bad news: the SPIKES strategy. Community Oncology 2005; 2(2):138-42.

13. Emmanuel LL, Ferris FF. Communicating bad news. In: Education in Palliative and End-of-life Care. Chicago: The EPEC Project. 1999.

14. Penson RT, Partridge RA, Shah MA, Giansiracusa D, Chabner BA, Lynch Jr TJ. Fear of death. Oncologist. 2005; 10(2):160-9.
15. Hagerty RG, Butow PN, Ellis PM, Dimitry S, Tattersall MH. Communicating prognosis in cancer care: a systematic review of the literature. Ann Oncol. $2005 ; 16(7): 1005-53$

16. Tulsky JA. Beyond advance directives: importance of communication skills at the end of life. JAMA. 2005; 294(3):359-65.

17. Audrey S, Abel J, Blazeby JM, Falk S, Campbell R. What oncologists tell patients about survival benefits of palliative chemotherapy and implications for informed consent: qualitative study. BMJ. 2008; 337:a752.

18. Castro EK, Barreto SM. Critérios de médicos oncologistas para encaminhamento psicológico em cuidados paliativos. Psicol Ciênc Prof. 2015; 35(1):69-82.

19. van Dulmen S, Tromp F, Grosfeld F, ten Cate O, Bensing J. The impact of assessing simulated bad news consultations on medical students' stress response and communication performance. Psychoneuroendocrinology. 2007; 32(8-10):943-50.

20. Schmidt Rio-Valle J, García Caro MP, Montoya Juarez R, Prados Peña D, Muñoz Vinuesa A, Pappous A, et al. Bad news for the patient and the family? The worst part of being a health care professional. J Palliat Care. 2009; 25(3):191-6.

21. Whitney SN, McCullough LB, Frugé E, McGuire AL, Volk RJ. Beyond breaking bad news: the roles of hope and hopefulness. Cancer. 2008; 113(2):442-5.

22. Minichiello TA, Ling D, Ucci DK. Breaking bad news: a practical approach for the hospitalist. J Hosp Med. 2007; 2(6):415-21.

23. Arbabi M, Roozdar A, Taher M, Shirzad S, Arjmand M, Mohammadi MR, et al. How to break bad news: physicians' and nurses' attitudes. Iran J Psychiatry. 2010; 5(4):128-33.

24. Fujimori M, Uchitomi Y. Preferences of cancer patients regarding communication of bad news: a systematic literature review. Jpn J Clin Oncol. 2009; 39(4):201-16.

25. Gulinelli A, Aisawa RK, Konno SN, Morinaga CV, Costardi WL, Antonio $\mathrm{RO}$, et al.Desejo de informação e participação nas decisões terapêuticas e em caso de doenças graves em pacientes atendidos em um hospital universitário. Rev Assoc Med Bras. 2004; 50(1):41-7.

26. Zarbock S. Giving bad news to patients: how to do it better. JAAPA. 2008 21(4):15.

27. Pessini L. Como lidar com o paciente em fase terminal. 5. ed. Aparecida: Santuário; 1990.

28. Blackhall LJ, Murphy ST, Frank G, Michel V, Azen S. Ethnicity and attitudes toward patient autonomy. JAMA. 1995; 274(10):820-5.

29. Lamont EB, Christakis NA. Prognostic disclosure to patients with cancer near the end of life. Ann Intern Med. 2001; 134(12):1096-105.

30. Turkoski BB. Ethics in the absence of truth. Home Healthc Nurse. 2001; 19(4):218-22.

31. Davis MP, Dreicer R. Revisiting truth and consequences: what to do when the patient doesn't want to know. J Clin Oncol. 2002; 20(21):4403-4.

32. Fallowfield LJ, Jenkins VA, Beveridge HA. Truth may hurt but deceit hurts more: communication in palliative care. Palliat Med. 2002; 16(4):297-303.

33. Pellegrino ED. Emerging ethical issues in palliative care. JAMA. 1998; 279(19):1521-2.

34. CREMESP. Doente terminal. Destino de pré-embriões. Clonagem. Meio Ambiente. Cadernos de Bioética do CREMESP. 2005; 1:8:41.

35. Ptacek JT, McIntosh EG. Physician challenges in communicating bad news. J Behav Med. 2009; 32(4):380-7.

36. Silva VCE, Zago MMF. A revelação do diagnóstico de câncer para profissionais e pacientes. Rev Bras Enferm. 2005; 58(4):476-80.

37. Hebert HD, Butera JN, Castillo J, Mega AE. Are we training our fellows adequately in delivering bad news to patients? A survey of hematology/ oncology program directors. J Palliat Med. 2009; 12(12):1119-24.

38. Carmo SA, Oliveira ICS. Criança com câncer em processo de morrer e sua família: enfrentamento da equipe de enfermagem. Rev Bras Cancerologia. 2015; 61(2):131-8

39. Trindade ES, Azambuja LEO, Andrade JP, Garrafa V. O médico frente ao diagnóstico e prognóstico do câncer avançado. Rev Assoc Med Bras. 2007; 53(1):68-74.

40. Barclay JS, Blackhall LJ, Tulsky JA. Communication strategies and cultural issues in the delivery of bad news. J Palliat Med. 2007; 10(4):958-77.

41. Pinheiro BF, Galvão KT, Sousa MNA, Lima CFS, Gonzaga MFLA. Acolhimento prestado por profissionais da saúde aos familiares de pacientes críticos. Revista FAMA de Ciências da Saúde. 2015; 1(1):28-35.

42. Fallowfield, L, Jenkins V. Communicating sad, bad, and difficult news in medicine. Lancet. 2004; 363(9405): 312-19.

43. Back AL, Arnold RM, Tulsky JA, Baile WF, Fryer-Edwards KA. Teaching communication skills to medical oncology fellows. J Clin Oncol. 2003; 21(12):2433-6. 